\title{
Ovarian Cancer in the Era of Immune Checkpoint Inhibitors: State of the Art and Future Perspectives.
}

\author{
Brigida Anna Maiorano ${ }^{1,2^{*}}$, Mauro Francesco Pio Maiorano ${ }^{3}$, Domenica Lorusso ${ }^{4}$ and Evaristo Maiello ${ }^{1}$ \\ 1 Oncology Unit, Foundation Casa Sollievo della Sofferenza IRCCS, 71013 San Giovanni Rotondo, Italy; \\ brigidamaiorano@gmail.com (B.A.M.), e.maiello@operapadrepio.it (E.M.) \\ 2 Department of Translational Medicine and Surgery, Catholic University of the Sacred Heart, 00168, Rome, \\ Italy; \\ 3 Division of Obstetrics and Gynecology, Biomedical and Human Oncological Science, University of Bari \\ "Aldo Moro", 70121 Bari, Italy; mauro.maiorano95@outlook.it (M.F.P.M.) \\ 4 Gynecologic Oncology Unit, Catholic University of the Sacred Heart; Scientific directorate, Fondazione \\ Policlinico “A.Gemelli” IRCCS, 00168, Rome, Italy; domenica.lorusso@policlinicogemelli.it (D.L.) \\ * Correspondence: brigidamaiorano@gmail.com
}

Simple Summary: Ovarian cancer (OC) represents the fifth cause of cancer-related deaths among women. In the advanced disease setting, OC recurrence after chemotherapy is over $70 \%$ in the first 2 years, having few therapeutic options. Immunotherapy with the immune checkpoint inhibitors (ICIs) showed high efficacy and changed the therapeutic scenario of many tumors in the last 10 years. With our review, we aimed to summarize the clinical trials of ICIs in the OC. Among the OC patients, unsatisfactory results in terms of responding patients and survival have been reported, and some studies failed to reach their objectives. Combining immunotherapy and other drugs with different mechanisms of action might enhance efficacy and overcome cancer resistance. The search for biomarkers predicting ICIs response is mandatory for better selection of potentially responding patients and design of clinical trials.

\begin{abstract}
Background: Ovarian cancer (OC) represents the eighth most common cancer and the fifth leading cause of cancer-related deaths among the female population. In the advanced setting, chemotherapy represents the first-choice treatment, despite a high recurrence rate. In the last ten years, immunotherapy based on immune checkpoint inhibitors (ICIs) has profoundly modified the therapeutic scenario of many solid tumors. We sought to summarize the main findings regarding the clinical use of ICIs in the OC. Methods: We searched the PubMed, Embase, and Cochrane Databases, and conference abstracts from international congresses (such as ASCO, ESMO, SGO) for clinical trials, focusing on ICIs both as monotherapy and as combinations in the advanced OC. Results: 20 studies were selected, of which 16 were phase I or II and 4 phase III trials. ICIs targeting PD1 (nivolumab, pembrolizumab), PD-L1 (avelumab, atezolizumab, durvalumab), and CTLA4 (ipilimumab, tremelimumab) were employed. No significant survival improvement was achieved; conversely, early terminations due to futility or toxicity were recorded. Combinations with chemotherapy, anti-VEGF, and, overall, PARP-inhibitors seem feasible and enhance the response rate and survival, notwithstanding a worse safety profile. Conclusions: The identification of biomarkers with a predictive role for ICIs' efficacy is mandatory. Moreover, genomic and immune profiling of the OC might lead to an improved treatments selection and design of tailored trials.
\end{abstract}

Keywords: Ovarian cancer, checkpoint inhibitors, ICIs, immunotherapy, PARP, avelumab, pembrolizumab, nivolumab, bevacizumab, platinum 


\section{Graphical Abstract}

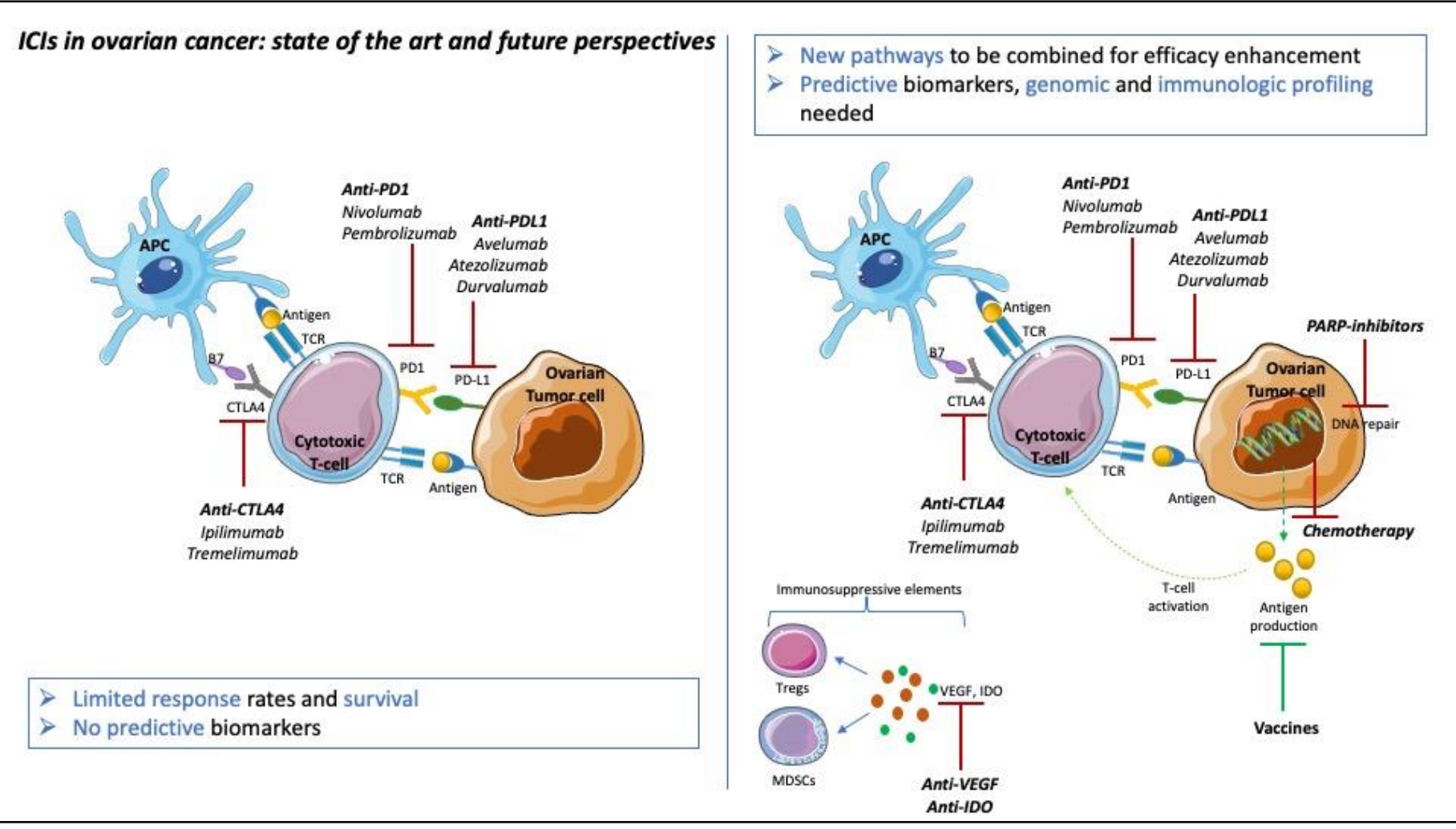




\section{Introduction}

Ovarian cancer (OC) accounts for about $2 \%$ of tumors, representing the eighth most common cancer among the female population. The incidence is around 11 cases $/ 100,000$ inhabitants/year, and it is higher among white women [1,2]. The frequency of OC rises with age, being uncommon before 30, and more frequently presenting at 50-70. Globally, ovarian cancer represents the fifth leading cause of female cancer-related deaths, with a $5 \mathrm{yr}$ survival rate falling from $90 \%$ at stage I to $25 \%$ at stage IV [2]. The majority of OCs have an epithelial origin, among whom serous carcinoma has the most aggressive features and is usually diagnosed at advanced stages [3]. Platinum-based chemotherapy regimens represent the mainstay of treatment [4-7]. The response to these agents and the treatmentfree interval (TFI) after platinum define the subsequent treatment, moving from the platinum-refractory (PR) (relapse $<6$ months from the platinum end) to the platinumsensitive (PS) patients (TFI $>12 \mathrm{mos}$ ). In fact, despite initial benefits, a disease recurrence occurs in over $2 / 3$ of patients within the first two years. Therefore, new drugs have been explored, and other agents such as the PARP-inhibitor (PARPi) agents and the antivascular endothelial growth factor (VEGF) bevacizumab have been approved in the advanced setting $[8,9]$.

Immunotherapy has represented a breakthrough therapy for many solid tumors [10]. So far, the best-studied mechanisms for inducing an immune response against tumors rely on inhibiting the immune checkpoint. The immune checkpoint inhibitors (ICIs) consist of monoclonal antibodies targeting Programmed Cell Death Protein 1 (PD-1)/Programmed Death-Ligand 1 (PD-L1) or Cytotoxic T-Lymphocyte Antigen 4 (CTLA-4), expressed by tumor or immune cells. After binding with these ligands, ICIs remove the inhibition signals for the immune system, unlocking the anti-tumor response [11]. However, in the OC, ICIs have reached modest results, and among the few phase III trials that have been conducted, some were even prematurely terminated for futility. Combinations with other compounds, such as PARPis or anti-angiogenic drugs, represent promising opportunities to enhance the clinical effectiveness of immunotherapy [12-36].

We hereinafter ought to synthesize the clinical trials involving ICIs that have been conducted in advanced OC to discuss the pros and cons and explore future perspectives to maximize the efficacy of immunotherapy for most women with advanced disease.

\section{Materials and Methods}

We searched the PubMed, EMBASE, and Cochrane databases and abstracts from international conferences (e.g., ASCO, ESMO, SGO). The terms ('ovarian cancer' OR 'ovarian carcinoma') AND ('immune checkpoint inhibitor' OR ICI OR avelumab OR nivolumab OR atezolizumab OR pembrolizumab OR durvalumab OR tremelimumab OR ipilimumab OR 'anti PD1' OR 'anti PD-L1' OR 'anti CTLA4') were used. Papers published in peer-reviewed journals and conference abstracts in the English language up to June 2021 were selected. We included clinical trials, whereas reviews, letters, and personal opinions were excluded. A total of 20 studies were included in our review.

\section{Results}

Since the FDA approved ipilimumab for advanced melanoma in 2011, the last ten years have been characterized by the widespread use of ICIs, thus revolutionizing the therapeutic algorithm of many solid tumors [10,37]. ICIs are monoclonal antibodies that unlock the anti-tumoral response of the host immune system through the inhibition of negative signals for effector T-cells. Among the ICIs tested in clinical trials in the OC, pembrolizumab and nivolumab target PD-1, atezolizumab, avelumab, and durvalumab bind PD-L1, ipilimumab, and tremelimumab are directed against CTLA-4. 17 phase I or II and 3 phase III trials have been published (Table 1). 


\subsection{Anti PD1 agents}

Nivolumab and Pembrolizumab have been tested as single agents and combined with other ICIs, chemotherapy, anti-angiogenic agents, and PARPis.

\subsubsection{Pembrolizumab}

In the KEYNOTE-100 (NCT02674061) phase II study, pembrolizumab $200 \mathrm{mg}$ q3w was administered to two cohorts of patients with recurrent ovarian cancer (ROC): cohort A enrolled 285 patients after 1 to 3 prior therapies with a treatment-free interval (TFI) of 3-12 months; cohort B included 91 progressive patients to up to six previous lines with a TFI of at least 3 mos. The primary endpoint was overall response rate (ORR) by Response Evaluation Criteria in Solid Tumors (RECIST) criteria and according to PD-L1 expression. Secondary endpoints included: duration of response (DoR), disease-control rate (DCR), progression-free survival (PFS), overall survival (OS), and safety. The combined ORR of the two cohorts was $8.0 \%$, the overall DCR $37 \%$, and around $1 / 3$ of responses lasted more than 6 months. The mDoR was 8.2 mos in cohort $A$ and not reached in cohort $B$. The mPFS was 2.1 mos [12]. PD-L1 positive patients (defined as a combined positive score-[CPS] $\geq 10)$ reached better results than PD-L1 negative, in terms of both ORR $(17.1 \%)$ and mOS (21.9 mos - cohort A, and 24.0 mos - cohort B) $[12,13]$. The most common adverse events (AEs) were fatigue $(33.8 \%)$, nausea $(15.4 \%)$, and decreased appetite $(10.6 \%)$, with $19.7 \%$ of women experiencing $>$ G3 AEs. The most common immune-related AEs (irAEs) were thyroid disorders (17.5\%). $5.1 \%$ of patients discontinued the treatment due to toxicity, and two treatment-related deaths were recorded [12].

In the Keynote-028 (NCT02054806) multi-cohort phase Ib trial, only PD-L1 positive patients were included. 26 women were treated with pembrolizumab in the OC cohort. The ORR represented the primary endpoint. After a median follow-up of 15.4 mos, ORR was $11.5 \%$, mPFS 1.9 mos, and mOS was 13.8 mos. $73.1 \%$ of patients experienced at least one treatment-related adverse event (TRAE): arthralgia (19.2\%), nausea (15.4\%), and pruritus $(15.4 \%)$ were the most common. One G3 hypertransaminasemia was recorded, while no deaths or treatment discontinuation for toxicity occurred [14].

Attempts to combine pembrolizumab were made with chemotherapy, bevacizumab, or PARPis. Pembrolizumab plus liposomal doxorubicin (PLD) determined an ORR of $19 \%, 3$ PR, and 1 SD > 24 weeks, among 26 platinum-resistant patients, with no G4 or G5 toxicities. G2 pneumonitis occurred in $8 \%$ of patients. G3 AEs included rash (19\%) and ALT increase (8\%) [15]. In the NCT02853318 phase II trial, 40 platinum-progressive OC women were treated with pembrolizumab plus bevacizumab plus oral cyclophosphamide. The study met its primary endpoints, reaching an ORR of $47.5 \%$ and an mPFS of 10 mos. The 6-month PFS rate was $100 \%$ for the PS-ROC and $59 \%$ for the PRROC patients $(\mathrm{p}=0.024)$. The most frequent AEs were fatigue $(45.0 \%)$, diarrhea $(32.5 \%)$, and hypertension (27.5\%), while the most common $\geq \mathrm{G} 3$ AEs were hypertension (15.0\%) and lymphopenia (7.5\%) [16]. The TOPACIO/Keynote-162 (NCT02657889) was a phase I/II study evaluating the combination of pembrolizumab plus the PARPi niraparib, conducted among triple-negative breast cancer and ROC patients. In the PR-ROC cohort, 62 patients were treated. The ORR (primary endpoint of the study) was $25 \%$, the DCR was $68 \%$. In the Breast cancer gene (BRCA)-mutant population, ORR and DCR were $45 \%$ and $73 \%$, respectively. The most frequent $\geq$ G3 TRAEs were anemia $(21 \%)$ and thrombocytopenia (9\%). No treatment-related deaths were recorded [17].

\subsubsection{Nivolumab}

As a single agent, nivolumab was administered to 20 patients with PR-ROC in the UMIN000005714 phase II trial, evaluating the best overall response (BOR) as a primary endpoint: 2 complete responses (CR) were recorded, the DCR was $45 \%$, the mPFS 3.5 mos, 
and the mOS 20.0 mos. Of note, $\geq$ G3 TRAEs occurred in $40 \%$ of patients. Two patients $(10 \%)$ experienced serious TRAEs, and $11 \%$ of patients discontinued Nivolumab treatment mainly due to treatment-related thyroid disorders [18].

In the NRG-GY003 phase II study (NCT02498600), nivolumab alone or plus ipilimumab was administered to 100 platinum-progressing ROC patients. The primary endpoint was ORR; secondary endpoints included PFS and OS, stratified by the platinumfree interval (PFI). The combination of nivolumab and ipilimumab vs. nivolumab alone resulted in increased ORR ( $31.4 \%$ vs. $12.2 \%$; $(\mathrm{p}=0.034)$, longer PFS ( 3.9 vs. 2 mos; $\mathrm{HR}=0.53$, 95\% CI 0.34-0.82) and longer OS (28.1 vs. 21.8 mos; HR=0.79, 95\% CI 0.44-1.42). However, the combination treatment was less tolerated (>G3 AEs $49 \%$ vs. 33\%). The response was not associated with PD-L1 status [19].

The combination of nivolumab plus bevacizumab was tested in 38 platinumprogressing epithelial ovarian cancer (EOC) patients in the NCT02873962 phase II study. ORR was the primary endpoint, while secondary endpoints were ORR according to platinum sensitivity and PD-L1 expression, PFS, and safety. The combination of nivolumab plus bevacizumab resulted in an ORR of $28.9 \%$, ranging from $16.7 \%$ in the platinum-resistant $(\mathrm{n}=18)$ to $40.0 \%$ in the platinum-sensitive patients $(\mathrm{n}=20)$. Median PFS was 9.4 mos and $12.1 \mathrm{mos}$ in the overall and platinum-sensitive population, respectively. Of note, better response rates were observed in patients with PD-L1 negative than PD-L1 positive disease. $89.5 \%$ of patients developed AEs, of whom the most common were fatigue $(47.4 \%)$, headache $(28.9 \%)$, myalgia $(28.9 \%)$, serum amylases increase $(28.9 \%)$, aspartate aminotransferase level increase (26.3\%), hypertension (26.3\%). 4 pneumonitis $(10.5 \%)$ and 2 colitis (5.3\%) were reported [20].

A unique phase III trial (NINJA) has been conducted in the Japanese population, randomizing patients with PR-ROC to nivolumab $(n=157)$ versus gemcitabine or PLD $(n=159)$ at physician's choice. However, the trial failed its primary endpoint, as there was no difference between the two groups for $\mathrm{OS}$ ( $\mathrm{HR}=1.03,95 \% \mathrm{CI}, 0.8-1.32 ; \mathrm{p}=0.8)$. Moreover, mPFS was shorter in the nivolumab group $(2.04 \mathrm{mos})$ than in the gem/PLD group (3.84 mos; $\mathrm{HR}=1.46,95 \% \mathrm{CI}, 1.15-1.85 ; \mathrm{p}=0.002$ ) The incidence of $\geq \mathrm{G} 3$ AEs was $22.4 \%$ with nivolumab and $68.4 \%$ with gem/PLD [21].

\subsection{Anti-PD-L1 agents}

\subsubsection{Avelumab}

In the OC cohort of the JAVELIN (NCT01772004) phase Ib study, avelumab $10 \mathrm{mg} / \mathrm{kg}$ $\mathrm{q} 2 \mathrm{w}$ determined an objective response in 12/125 patients, including $1 \mathrm{CR}$ and 11 partial responses (PR). The 1-yr PFS rate was 10.2\% (95\%CI, 5.4\%-16.7\%), the mPFS 2.6 months (95\%CI, 1.4-2.8 mos), and the mOS 11.2 months (95\%CI, 8.7-15.4 mos). The responses were recorded independently from PD-L1 expression. The most frequent AEs were fatigue $(13.6 \%)$, diarrhea $(12.0 \%)$, and nausea $(11.2 \%)$. $\geq \mathrm{G} 3$ AEs occurred in $7.2 \%$ of patients, among which the most frequent was the increase in lipase level (2.4\%) [22].

The combination of avelumab plus chemotherapy was tested in two randomized phase III trials. The JAVELIN Ovarian 100 (NCT02718417) evaluated carboplatinpaclitaxel chemotherapy alone versus chemotherapy plus avelumab followed by avelumab maintenance versus chemotherapy plus avelumab in the front line OC setting. 998 stage III-IV patients were enrolled. The primary endpoint was PFS. However, after a median follow-up of 11 mos, PFS was not improved in both avelumab arms, and the trial was stopped after meeting futility criteria [23]. Based on the absence of benefit from Avelumab in unselected patients, the JAVELIN Ovarian PARP 100 (NCT03642132) phase III study, with three arms consisting of chemotherapy plus avelumab followed by maintenance with avelumab plus talazoparib, chemotherapy followed by talazoparib maintenance, and chemotherapy plus bevacizumab followed by bevacizumab, was also terminated [24]. 
In the JAVELIN 200 (NCT02580058) phase III study, 566 patients with PR-ROC were randomized 1:1:1 to avelumab alone or avelumab plus PLD or PLD alone. PFS and OS were the co-primary endpoints. The combination group achieved a non significant longer OS (15.7 mos; HR vs PLD 0.89, 95\%CI, 0.74-1.24, p=0.2) and PFS (3.7 mos, HR 0.78, 95\% CI, 0.59-1.24; $\mathrm{p}=0.03$ ) with respect to PLD single agent. Avelumab alone compared to PLD did not improve either OS (HR=1.14, 95\% CI, 0.95-1.58; $\mathrm{p}=0.82$ ) or PFS ( $\mathrm{HR}=1.68,95 \% \mathrm{CI}, 1.32$ 2.60; $\mathrm{p}>0.99)$. A longer PFS and OS trend was observed in the avelumab + PLD arm vs. PLD arm among the PD-L1+ patients (58\%). In the avelumab, avelumab plus PLD, and PLD arms, $\geq$ G3 TRAEs occurred in $49.7 \%, 68.7 \%$, and $59.3 \%$ of patients, respectively [25].

In the phase II ENCORE-603 study, 126 patients with PR-ROC were randomized 2:1 to avelumab plus the class I selective histone deacetylase (HDAC) inhibitor entinostat or avelumab plus placebo (PBO), with PFS as the primary endpoint. No significant differences were detected between the two groups for mPFS (1.64 vs. 1.51 mos; HR=0.9, 95\% CI, 0.58-1.39; $\mathrm{p}=0.031$ ), ORR, and OS. AEs were more frequent with the avelumabEntinostat combination than with avelumab-PBO (93\% vs. $78 \%$, $\geq \mathrm{G} 3$ AEs $41 \%$ vs. $10 \%)$, fatigue, nausea, diarrhea, anemia, and chills being the most frequent [26].

\subsubsection{Atezolizumab}

In the randomized phase III IMagyn050/GOG 3015/ENGOT-OV39 trial, 1,301 stage III/IV OC patients were treated with the combination of carboplatin, paclitaxel and bevacizumab plus or minus atezolizumab (1200 mg q3w). The PFS improvement was not significant both in the overall population (19.5 vs. 18.4 mos $\mathrm{HR}=0.92 ; 95 \% \mathrm{CI}, 0.79-1.07$; $\mathrm{p}=0.28$ ) and among the PD-L1 positive patients ( 20.8 vs. 18.5 mos HR=0.8; $95 \% \mathrm{CI}, 0.65$ 0.99; $\mathrm{p}=0.38$ ). Similarly, no benefit emerged at the interim analysis for OS. Anemia, neutropenia, and hypertension were the most common $\geq \mathrm{G} 3$ AEs [27].

\subsubsection{Durvalumab}

Durvalumab was tested in combination with chemotherapy, PARPis, or anti-VEGF agents.

In the NCT02431559 phase I/II trial, 40 PR-ROC women received durvalumab plus PLD, reaching an ORR of $15 \%$ and a 6 -mos PFS rate of $47.7 \%$. The most frequent TRAEs were palmar-plantar erythrodysesthesia syndrome (PPES), stomatitis, fatigue, abdominal pain, nausea, fever. G3 TRAEs occurred in at least 2 patients included lymphopenia, anemia, increased lipase, rash, and stomatitis [28].

The association of durvalumab and olaparib was tested in three phase II studies. The MEDIOLA study aimed to evaluate 12 -wks DCR and safety as primary endpoints, plus 28-wks DCR, ORR, DOR, PFS, OS as secondary endpoints. Initially, 32 women with BRCA-mutant PS-ROC were included. 12-wks DCR was $81 \%$ [29]. After a median followup of 20.4 mos, 28 -wks DCR was $65.6 \%$ with mPFS 11.1 mos, ORR $71.9 \%$, and mOS was not reached [30]. Subsequently, the study included 63 BRCA-wild type patients. 32 patients received durvalumab plus olaparib, 31 patients were treated with olaparib plus durvalumab plus bevacizumab. The doublet cohort reached an ORR of 31.3\% (95\% CI $16.1-50.0 \%$ ) vs. $77.4 \%$ in the triplet cohort (95\% CI 58.9-90.4\%). The mPFS was 5.5 mos for the doublet cohort and 14.7 mos for the triplet cohort, respectively. 24-wks DCR was $28.1 \%$ in the doublet cohort and $77.4 \%$ in the triplet cohort. The most common $\geq \mathrm{G} 3$ AEs were anemia, neutropenia, and lipase increased in both cohorts, while in the triplet cohort hypertension and fatigue were also registered. $6 \%$ and $16 \%$ of patients discontinued the treatment in the double and triplet cohorts, respectively [31]. In the dose-escalation phase I/II NCT02484404 trial, among 35 patients with ROC, a DCR of 53\% was observed with durvalumab plus olaparib or cediranib (5 PR, 13 stable disease [SD]). $\geq \mathrm{G} 3$ AEs included anemia (26\%) and lymphopenia (14\%) [32]. In a third single-center study (NCT02484404), 35 patients with PR-ROC were included. The (primary endpoint) ORR was $14 \%$. Exploratory analyses showed that an increased gamma-interferon $(\gamma$-IFN) production 
was associated with longer PFS ( $\mathrm{p}=0.023$ ), whereas increased vascular endothelial growth factor receptor (VEGFR)-3 levels determined shorter PFS ( $p=0.017$ ). Haematologic toxicity caused the highest $\geq \mathrm{G} 3$ AEs (most frequently anemia, 31\%) [33].

\subsection{Anti CTLA-4}

Few trials have explored the activity of single agents anti-CTLA-4 Ipilimumab or Tremelimumab in the advanced/recurrent OC with unsatisfactory results. In the NCT01611558 phase II trial with ipilimumab at the dose of $10 \mathrm{mg} / \mathrm{kg}$, 38 out of 40 PR-ROC patients did not complete treatment due to PD, severe toxicity, or death [34]. The combination with PARPis is still at an early stage but seems to be tolerated and induces anti-tumor responses. More specifically, 24 PR-ROC patients received tremelimumab alone or combined with olaparib in the NCT02485990 phase II trial, with 1 PR and 9 SD. No G4 AEs were reported, while the most common G3 toxicities were rash (13\%), hepatitis, and colitis (both 8\%) [35]. The same combination was administered to 3 BRCAmutant OC patients in the NCT02571725 phase I trial, with a good safety profile (only G1/2 AEs were reported) and decreased tumor size after three cycles [36].

Table 1. Trials of ICIs in the OC setting.

\begin{tabular}{|c|c|c|c|c|c|}
\hline Study name & Phase & $\begin{array}{l}\text { Target population } \\
\text { (number of pts) }\end{array}$ & $\begin{array}{l}\text { Administered } \\
\text { drugs }\end{array}$ & $\begin{array}{l}\text { Primary } \\
\text { EP }\end{array}$ & Results \\
\hline $\begin{array}{r}\text { Keynote } \\
\text { (NCT026740 }\end{array}$ & II & $\begin{array}{l}\text { Cohort A } \\
\text { ROC after 1-3 } \\
\text { therapies, TFI 3-12 } \\
\text { mos }(n=285) ; \\
\text { Cohort B } \\
\text { ROC after } 6 \text { lines, } \\
\text { TFI }>3 \text { mos }(n=91)\end{array}$ & Pembrolizumab & $\begin{array}{l}\text { ORR } \\
\text { (RECIST } \\
\text { and by } \\
\text { PD-L1) }\end{array}$ & $\begin{array}{c}\text { ORR } 8.0 \% \text {, DC } \\
\text { R 37\% (overall), } 1 / 3 \text { responses >6mos; mDOR } \\
\text { (A), NR (B); mPFS } 2.1 \text { mos; } \\
\text { PD-L1+: ORR 17.1\%, OS } 21.9 \text { (cohort A) and } \\
24.0 \text { mos (B); } \\
\geq \text { G3 AEs: } 19.7 \% ; 2 \text { treatment-related deaths. }\end{array}$ \\
\hline $\begin{array}{c}\text { Keynote-028 } \\
(\mathrm{NCT} 02054806)^{[14]}\end{array}$ & $\mathrm{Ib}$ & PD-L1+ ROC $(n=26)$ & Pembrolizumab & ORR & $\begin{array}{r}\text { ORR } 11.5 \% \text {, mPFS } 1.9 \\
\text { AEs } 73.1 \% \\
\end{array}$ \\
\hline NCT02865811[15] & II & $\begin{array}{l}\text { PR-ROC, fallopian } \\
\text { tube or peritoneal } \\
\quad \text { cancer }(n=26)\end{array}$ & $\begin{array}{l}\text { Pembrolizumab } \\
+ \text { PLD }\end{array}$ & $\begin{array}{c}\text { Clinical } \\
\text { Benefit } \\
\text { Rate (CR, } \\
\text { PR, SD) }\end{array}$ & $\begin{array}{l}\text { ORR } 19 \%, 3 \text { PR, } 1 \text { SD>24 wks) } \\
\geq \text { G3 AEs: rash (19\%), } \uparrow \text { ALT (8\%) }\end{array}$ \\
\hline NCT02853318[16] & II & $\begin{array}{l}\text { PS- and PR-ROC } \\
\quad(n=40)\end{array}$ & $\begin{array}{l}\text { Pembrolizumab } \\
+ \text { bevacizumab }+ \\
\text { cyclophosphami } \\
\text { de }\end{array}$ & $\begin{array}{l}\text { ORR, } \\
\text { mPFS }\end{array}$ & $\begin{array}{c}\text { ORR } 47.5 \% \text {, mPFS } 10 \text { mos; 6mos PFS: } 100 \% \\
\text { (PS-ROC), 59\% (PR-ROC) ( } \mathrm{p}=0.024) \\
\text { <G3 AEs: fatigue (45.0\%), diarrhea (32.5\%), } \\
\text { hypertension (27.5\%); } \geq \text { G3: hypertension } \\
(15.0 \%), \text { lymphopenia }(7.5 \%) .\end{array}$ \\
\hline $\begin{array}{l}\text { TOPACIO/ Keynote- } \\
162 \\
\left(\text { NCT02657889) }{ }^{[17]}\right.\end{array}$ & I-II & PR-ROC $(n=62)$ & $\begin{array}{l}\text { Pembrolizumab } \\
\quad+\text { niraparib }\end{array}$ & ORR & $\begin{array}{c}\text { ORR 25\%, DCR 68\%; BRCAm: ORR 45\%, } \\
\text { DCR 73\% } \\
\geq \text { G3 AEs: anemia ( } 21 \%), \text { thrombocytopenia } \\
(9 \%) .\end{array}$ \\
\hline UMIN000005714[18] & II & PR-ROC ( $n=20)$ & $\begin{array}{l}\text { Nivolumab }(1 \\
\text { and } 3 \mathrm{mg} / \mathrm{kg})\end{array}$ & BOR & $\begin{array}{l}2 \text { CR; DCR } 45 \% \text {; mPFS } 3.5 \text { mos; mOS } 20 \text { mos } \\
\geq \text { G3 AEs } 40 \% \text {, } 2 \text { SAEs, } 11 \% \text { discontinuation. }\end{array}$ \\
\hline $\begin{array}{c}\text { NRG-GY003 } \\
(\text { NCT02498600) } \\
{\left[{ }^{[19]}\right.}\end{array}$ & II & $\begin{array}{l}\text { PS- and PR-ROC } \\
\qquad(n=100)\end{array}$ & $\begin{array}{l}\text { Nivolumab vs. } \\
\text { nivolumab }+ \\
\text { ipilimumab } \rightarrow \\
\text { nivolumab } \\
\text { maintenance }\end{array}$ & ORR & $\begin{array}{l}\text { ORR 31.4\% }(\mathrm{N}+\mathrm{I}) \text { vs. } 12.2 \%(\mathrm{~N})(\mathrm{p}=0.034) \\
\text { PFS 3.9 }(\mathrm{N}+\mathrm{I}) \text { vs. } 2(\mathrm{~N}) \operatorname{mos}(\mathrm{HR}=0.53) ; \mathrm{OS} \\
28.1(\mathrm{~N}+\mathrm{I}) \text { vs. } 21.8(\mathrm{~N}) \text { mos }(\mathrm{HR}=0.79) ; \\
\text { responses not associated with PD-L1 } \\
\quad \geq \mathrm{G} 3 \text { AEs: } 33 \%(\mathrm{~N}), 49 \%(\mathrm{~N}+\mathrm{I})\end{array}$ \\
\hline
\end{tabular}


NCT02873962[20] II PS- and PR-EOC Nivolumab + $(n=38)$
ORR: 28.9\% (40\% PS-ROC, PR-ROC 16.7\%); mPFS 9.4 mos (12.1 mos PS-ROC); PD-L1better than PD-L1+ pts.

AEs $89.5 \%$ : fatigue (47.4\%), headache ORR (28.9\%), myalgia (28.9\%), $\uparrow$ amylase (28.9\%),

$\uparrow$ AST $(26.3 \%)$, hypertension $(26.3 \%)$; pneumonitis $(10.5 \%)$, colitis $(5.3 \%)$. $\geq$ G3 AEs $23.7 \%$.

No OS differences (HR=1.03); PFS 2 (N) vs Nivolumab vs. OS $\quad 3.8 \mathrm{mos}(\mathrm{gem} / \mathrm{PLD})(\mathrm{HR}=1.46 ; \mathrm{p}=0.002)$ $\geq$ G3 AEs: $22.4 \%$ (N), 68.4\% (gem/PLD) 1/125 CR, 11/125 PR; 1-yr PFS: 10.2\%; mOS: PLD 11.2 mos; mPFS: 2.6 mos $\geq$ G3 AEs $7.2 \%$ ( $\uparrow$ lipase $2.4 \%$ )

Ave + PLD: PFS 3.7 mos (HR vs. PLD $=0.78$, $\mathrm{p}=0.03)$, OS 15.7 mos (HR vs. PLD=0.89, $\mathrm{p}=0.2)$; avelumab vs. PLD HR for $\mathrm{OS}=1.14$,

Avelumab PLD vs. PLD HR for PFS=1.68

PD-L1+: trend for longer PFS and OS Ave+PLD vs. PLD

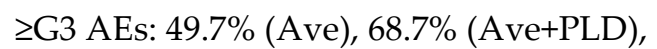
$59.3 \%$ (PLD)

mPFS=1.64 (A+E) vs. $1.51 \operatorname{mos}(\mathrm{A}+\mathrm{P})$ $(p=0.031)$. No differences in ORR (6\% vs $5 \%$ ), or OS (NE vs 11.3 mos)

AEs: $93 \%(\mathrm{~A}+\mathrm{E}), 78 \%(\mathrm{~A}+\mathrm{P})$; $\geq \mathrm{G} 3$ AEs: $41 \%$ $(\mathrm{A}+\mathrm{E}), 10 \%(\mathrm{~A}+\mathrm{P})$

CHT (CBDCA + paclitaxel + PFS/OS in

IMagyn050
(NCT03038100) $)^{[27]}$$\quad \begin{gathered}\text { First-line OC } \\ (n=1,301)\end{gathered}$
bevacizumab + ITT and atezolizumab vs PD-L1+

PFS 19.5 vs. $18.4 \operatorname{mos}(\mathrm{HR}=0.92 ; \mathrm{p}=0.28)$; $\mathrm{PD}-$ L1+ PFS: 20.8 vs $18.5 \operatorname{mos}(\mathrm{HR}=0.8 ; \mathrm{p}=0.38)$; no OS advantage.

$\mathrm{CHT}+$ beva + population $\mathrm{PBO}$

$\geq G 3$ : neutropenia, hypertension, anemia.

\begin{tabular}{|c|c|c|c|c|}
\hline NCT02431559[28] & I-II & PR-ROC $(n=40)$ & $\begin{array}{l}\text { Durvalumab + } \\
\text { PLD }\end{array}$ & PFS6 \\
\hline & & & $\begin{array}{c}\text { gBRCAm group: } \\
\text { olaparib (4 wks) } \\
\rightarrow \text { durvalumab + } \\
\text { olaparib }\end{array}$ & \\
\hline $\begin{array}{c}\text { MEDIOLA } \\
(\text { NCT02734004) })^{[29-31]}\end{array}$ & II & $\begin{array}{c}\text { gBRCAm }(n=32) \text { and } \\
\text { BRCAwt }(n=63) \text { PS- } \\
\text { ROC }\end{array}$ & $\begin{array}{c}\text { BRCAwt group: } \\
\text { durvalumab + } \\
\text { olaparib }(\mathrm{D}+\mathrm{O} ; \\
\mathrm{n}=32), \\
\text { durvalumab + } \\
\text { olaparib + } \\
\text { bevacizumab } \\
(\mathrm{D}+\mathrm{O}+\mathrm{B} ; \mathrm{n}=31)\end{array}$ & $\begin{array}{l}12 \mathrm{wks} \\
\text { DCR, } \\
\text { safety }\end{array}$ \\
\hline
\end{tabular}

\section{PFS6: 47.7\%; ORR 15\%}

G3 Aes in $\geq 2$ pts: lymphopenia, anemia, lipase increased, rash, stomatitis gBRCAm group: 12wks DCR 81\%, mPFS 11.1 mos, ORR 71.9\%

BRCAwt D+O group: ORR 31.3\%, mPFS 5.5 mos,

24wks DCR 28.1\%; 6\% discontinuation

BRCAwt D+O+B group: ORR 77.4\%, mPFS 14.7 mos, 24wks DCR 77.4\%; 16\% discontinuation

$\geq$ G3 AEs: anemia, lipase increased, neutropenia; + hypertension, fatigue (O+D+B cohort) 


\begin{tabular}{|c|c|c|c|c|c|}
\hline NCT02484404[32] & I-II & PS/PR-ROC (n=35) & $\begin{array}{c}\text { Durvalumab }+ \\
\text { olaparib or } \\
\text { cediranib } \\
\end{array}$ & RP2D & $\begin{array}{c}5 \text { PR, } 13 \text { SD, DCR } 53 \% \\
\geq \mathrm{G} 3 \text { AEs: anemia (26\%), lymphopenia (14\%) }\end{array}$ \\
\hline NCT02484404[33] & II & PR-ROC ( $n=35)$ & $\begin{array}{l}\text { Durvalumab + } \\
\text { olaparib }\end{array}$ & ORR & $\begin{array}{c}\text { ORR } 14 \% \text {; longer PFS with } \uparrow \text { IFN } \gamma(\mathrm{p}=0.023) \\
\text { shorter PFS with } \uparrow \text { VEGFR3 }(\mathrm{p}=0.017) \\
\geq \mathrm{G} 3 \text { AE: anemia }(31 \%) .\end{array}$ \\
\hline NCT02485990[35] & I-II & PR-ROC ( $n=24)$ & $\begin{array}{l}\text { Tremelimumab } \\
\text { vs. } \\
\text { tremelimumab + } \\
\text { olaparib }\end{array}$ & $\begin{array}{l}\text { RP2D, } \\
\text { ORR }\end{array}$ & $\begin{array}{c}1 \mathrm{PR}, 9 \mathrm{SD} \\
\geq \mathrm{G3} \text { AEs: rash (13\%), hepatitis (8\%), colitis } \\
(8 \%) ; \text { no } \geq \mathrm{G} 4 \text { AEs. }\end{array}$ \\
\hline NCT02571725[36] & I-II & BRCAm OC $(n=3)$ & $\begin{array}{l}\text { Tremelimumab + } \\
\text { olaparib }\end{array}$ & RP2D & $\begin{array}{c}\text { G1/2 AEs, decreased tumor size after } 3 \\
\text { cycles }\end{array}$ \\
\hline
\end{tabular}

AE: adverse event; ALT: alanine aminotransferase; AST: aspartate aminotransferase; BOR: best overall response; BRCAwt: BRCAwild type; CBDCA: carboplatin; CHT: chemotherapy; CR: complete response; DCR: disease control rate; DoR: duration of response; EOC: epithelial ovarian cancer; EP: endpoint; gBRCAm: germline BRCA-mutated; ICI: immune-checkpoint inhibitor; ITT: intentionto-treat; mOS: median overall survival; mPFS: median progression free survival; OC: ovarian cancer; ORR: overall response rate; PBO: placebo; PD-L1: programmed death ligand 1; PFS6: 6-months progression free survival; PLD: pegylated liposomal doxorubicin; PO: orally; PR: partial response; PR-ROC: platinum-resistant recurrent ovarian cancer; PS-ROC: platinum-sensitive recurrent ovarian cancer; RP2D: recommended phase II dose; SD: stable disease; TFI: treatment-free interval; VEGFR: vascular endothelial growth factor receptor.

\section{Discussion}

Given the impact on morbidity and mortality among the female population, the search for new therapeutic options represents an unmet need for OC. Immunotherapy has revolutionized the treatment landscape of many solid tumors in the last ten years, and it now represents the first therapeutic approach with impressive survival benefits in diseases such as lung cancer, melanoma, renal cell carcinoma [10]. However, limited benefits have emerged in the $\mathrm{OC}$, even leading to the premature termination for the futility of some studies. Different components of the OC tumor microenvironment (TME) contribute to this failure, such as myeloid-derived suppressor cells (MDSCs), tumorassociated macrophages (TAMs), T-cells, cytokines, and soluble factors [37-40]. MDSCs exert immunosuppressive functions, such as the inhibition of T-effector and natural killer (NK)-cells, and are induced under pro-inflammatory cytokines, IFN $\gamma$, tumor necrosis factor-alpha (TNF $\alpha$ ), interleukin (IL)-6 [41]. In the OC, IL-6 plays a negative prognostic role and is associated with high MDSCs, and tumor progression [42, 43]. The inflammatory cytokines cooperate to induce cyclooxygenase-2 (COX-2) and lead to prostaglandin E2 (PGE2) synthesis, which limits T-cell recruiting at tumor sites, together with VEGF [44, 45]. TAMs are recruited at ovarian tumor sites, and IL-6, IL-10, transforming growth factor (TGF)- $\beta$ promote their differentiation in M2 macrophages, associated with tumor invasiveness, spread, and angiogenesis [46-48]. M2 macrophages increase with the OC stage when contemporary M1 macrophages decrease, playing a negative prognostic role [49-51]. Moreover, they promote immunosuppression by producing cytokines (IL-1R, IL-10, C-C Motif Chemokine Ligand [CCL]17, CCL20, CCL22) that inhibit T-effectors proliferation and enhance Tregs function [52-54]. Treg cells are associated with advanced stages of $O C$, thus having a negative prognostic and immunosuppressive role [54]. They produce IL-10 and TGF $\beta$, contributing to the inhibition of effector T-cells [55]. High levels of immunosuppressive elements within the OC TME can also weaken dendritic cells and antigen-presenting cells (APCs) activity [56]. More accurate knowledge of the TME of the primary tumors and the metastatic sites allows better selection and treatment combination (Figure 1). 


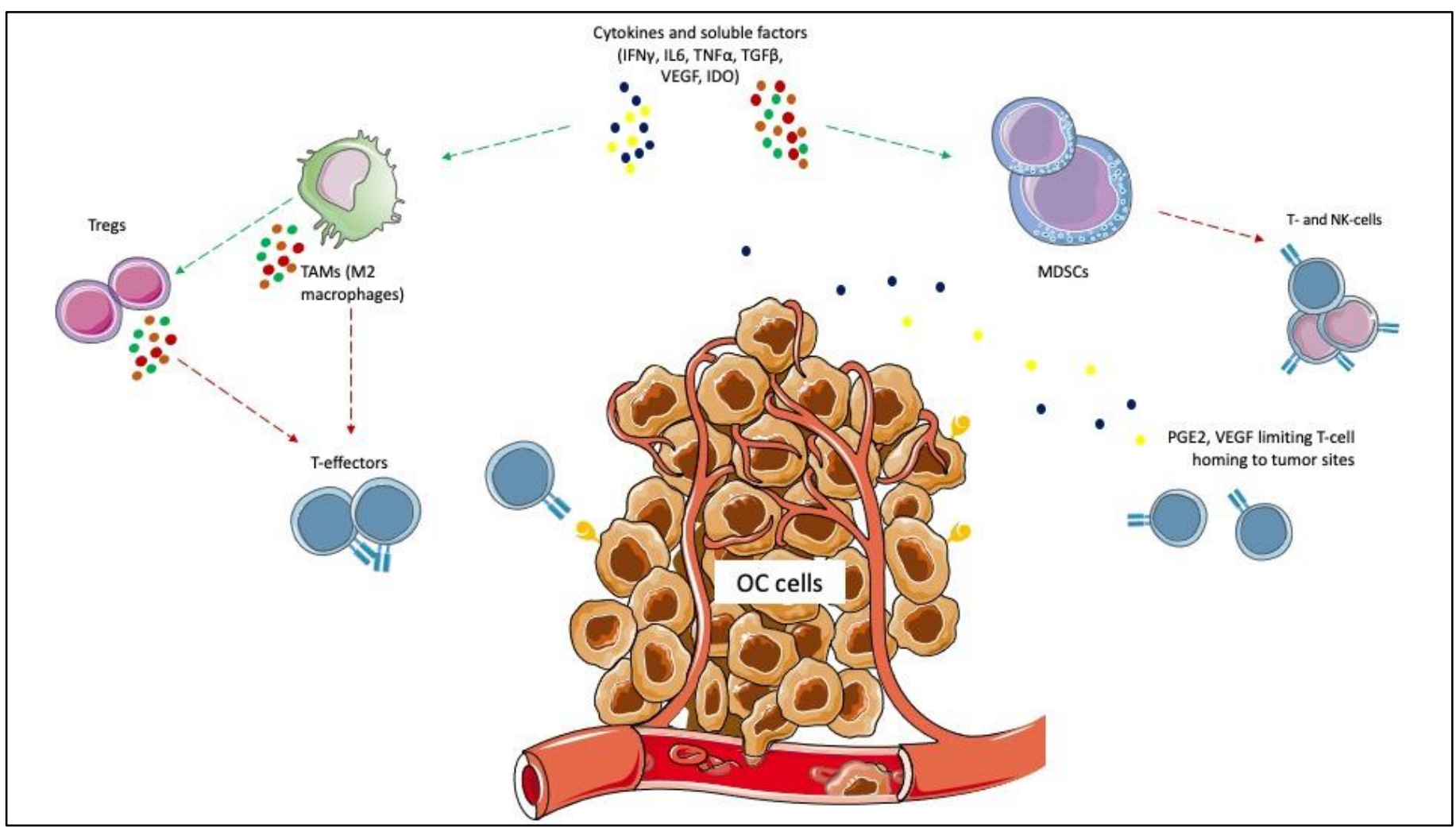

Figure 1. Immunosuppressive elements of ovarian cancer (OC) microenvironment. Cytokines and other soluble factors, such as interferon-gamma (IFN $\gamma$ ), tumor necrosis factor-alpha (TNF $\alpha$ ), interleukin (IL)-6, IL-10, transforming growth factorbeta (TGF $\beta$ ) induce the proliferation of myeloid-derived suppressor cells (MDSCs) and the polarization of tumor-associated macrophages (TAMs) towards the M2 subtype. MDSCs exert immunosuppressive functions, such as the inhibition of Teffector and natural killer (NK)-cells. The inflammatory cytokines cooperate to induce cyclooxygenase-2 (COX-2) and lead to prostaglandin E2 (PGE2) synthesis, which limits T-cell recruiting at tumor sites. M2 macrophages promote immunosuppression by producing cytokines (e.g., IL-1R, IL-10, C-C Motif Chemokine Ligand [CCL]17, CCL20, CCL22) that inhibit T-effectors proliferation and enhance Tregs function.

Indeed, the category of OC encompasses a heterogeneous group of malignancies that in over $95 \%$ of cases have an epithelial origin and are more frequently represented by high grade serous ovarian carcinoma (HGSOC) (70\% of cases), followed by endometrioid ovarian cancer (EOC) $(10 \%)$, clear cell OC (ccOC) $(10 \%)$, low-grade serous OC (LGSOC, less than 5\%), and mucinous OC (MOC, around 3\%) [3]. Among them, the ccOC seems to be the most immunogenic: it more frequently carries the DNA microsatellite instability (MSI), has higher CD8+ tumor-infiltrating lymphocites (TILs), CD8+/CD4+ ratio, and higher PD-L1 levels [57, 58]. Effectively, it seems to be five times more responsive to ICIs than the other OC subtypes [19]. Even among the HGSOC, at least four different classes were identified in The Cancer Genomic Atlas registry, differing for immunoreactivity. A unique subtype expresses genes related to immune sensitivity such as Toll-like receptor (TLR), TNF and is characterized by higher TILs infiltration [59,60]. A deeper insight into the genomics characteristics of the different subtypes and their relationship with the immunological profile could allow us to better clarify the predictive factors for ICIs response.

The OC has been indicated as potentially more immune responsive when carrying BRCA mutations or homologous recombination deficiency (HRD). In fact, the impaired DNA repair leads to neo-antigens production, resulting in a higher tumor mutational burden (TMB) (even if $<10$ mutations per megabase are usually detected) and recruiting TILs at tumor sites. However, HRD or BRCA mutations were not linked to a higher sensitivity to ICIs in the IMagyn050 nor in the Javelin Ovarian 100 trials [23, 27]. BRCAmutant/HRD OC is associated with higher CD3+ and CD8+ TILs, PD1/PD-L1 levels, and 
genes related to cytotoxicity, such as T-Cell Receptor (TCR), $\gamma$-IFN, and TNF-Receptor pathway [61-64]. As proof of this, in the NCT02484404 trial, durvalumab plus olaparib determined a longer PFS in case of increased $\gamma$-IFN production [33]. Another mechanism of immune responsiveness is represented by the mismatch repair (MMR) deficiency, harboring the DNA MSI. MSI tumors produce neo-antigens, with a 10-100 fold higher TMB than MS stable (MSS)-tumors, resulting in high immunogenicity. Some genes triggering MSI have also been identified in a percentage ranging from $17 \%$ to $59 \%$ of OC (more commonly in non-serous subtypes): the oncosuppressor TP53; Dihydropyrimidinase-related protein (DPYSL)-2, involved in microtubules function; Alpha Kinase (ALPK)-2, with a role in apoptosis and DNA repair [65]. In the Lynch syndrome, a germline mutation of the MMR genes MutL homolog (MLH)-1, MutS homolog (MSH)-2 and -6, PMS1 homolog (PMS)-2 leads to an increased risk to develop some cancer subtypes, including OC [66]. Therefore, these tumors may be good candidates for ICIs treatment.

The possible relationship between platinum- and immunotherapysensitivity/resistance is also a field that merits further investigation [67]. A series of genetic and epigenetic elements have been identified to drive the response to platinum: alterations of p53, specific microRNAs, elements driving the epithelial-to-mesenchymal transition (EMT), the HRD, and BRCA mutations [68]. Since BRCA mutation and HRD have been proposed to correlate with platinum sensitivity in contemporary deficient nucleotide excision repair, the co-administration of PARPis and ICIs in PS-ROC could result in higher ORR and survival rates [29-31]. PARPis enhance ICIs activity because they induce the release of neoantigens, increasing the TMB, promote PD-L1 expression, and directly activate the IFN genes [69, 70]. A proof of this efficacy has been obtained in OC yet $[17,29-31]$. Moreover, many ongoing trials are addressing this combination strategy in the advanced setting (Table 2).

As ICIs monotherapies have shown only minimal results in terms of response rate and survival in OC, the combination with agents having different mechanisms of action appears a promising strategy to increase efficacy. Although chemotherapy represents a cornerstone in the treatment of advanced OC, it has historically been perceived to play an immunosuppressive role. On the contrary, more recently, it has emerged that platinum derivatives promote APCs and their function, thus activating the immune response [7174]. Doxorubicin plays an immunomodulatory effect, reducing the immunosuppressive state and improving the tumor sensitivity to NK and CD8+ T-cells [75]. Low-dose cyclophosphamide also holds immunomodulatory properties, such as Tregs reduction and CD8+ cells induction [76, 77]. However, the studies conducted so far did not lead to survival improvements. Besides the immunological potential, the timing and schedule should be more deeply investigated and optimized for improving efficacy. The combination of ICIs and anti-VEGF agents seems attractive because the anti-angiogenic drugs directly influence the OC TME [20, 31, 32, 78-80]. Other combinations with multikinase inhibitors targeting VEGF/VEGFRpathway, such as cabozantinib or lenvatinib, are now under evaluation. The association with other agents with immunotherapeutics role, such as the anti-Lymphocyte-activation gene 3 (LAG-3) Relatlimab, as well as monoclonal antibodies such as the anti-Cluster of differentiation (CD)27 Varlilumab, the anti-CD47 Magrolimab, is under investigation (Table 2). Actually, overcoming the immunosuppressive pathways in the TME could represent a complementary way to potentiate the ICIs effect on the immune system. Therapeutic vaccines have been administered in the $\mathrm{OC}$, inducing cellular and humoral responses but rarely survival improvement as monotherapies [81]. Hence, several tumor-associated antigens were found in the OC, such as p53, folate receptor (FR), New York Esophageal Squamous Cell Carcinoma-1 (NY-ESO-1), Ca125 [82-85]. Therefore, combinations of ICIs and vaccines need to be explored. New approaches such as autologous TILs, cancer cell therapy, and adoptive cell therapy (ACT) also represent future possibilities for improving ICIs efficacy (Table 2). 
Currently, a uniformly accepted predictive role of PD-L1 for ICIs response has not yet been identified in the different solid tumors, including OC. PD-L1 expression varies between primary tumors and metastases, implying heterogeneity in the tumor [86]. However, even if the PD-L1 positivity has been retrieved in around 1/3 OCs, the clinical impact has not been elucidated, with conflicting results regarding the association with higher tumor stage/grade or shorter survival [87-91]. Indeed, some of the published trials reported better results for PD-L1 positive than PD-L1 negative patients [12, 13, 27]. In other studies, the PD-L1 positivity was not predictive of ICIs response. Of note, these cases included combinations of ICIs and other drugs with different mechanisms of action, such as anti-VEGF, confirming that PD-L1 alone is not sufficient to predict the response to ICIs, particularly if associated with anti-VEGF drugs [20]. Similarly, the PD-L1 status did not impact the response to anti-PD-1 and anti-CTLA-4 agents [19]. Therefore, biomarkers with a predictive role for ICIs' efficacy are warranted to ensure the best patient selection.

Table 2. Ongoing trials of ICIs combinations in the metastatic OC.

\begin{tabular}{|c|c|c|}
\hline $\begin{array}{l}\text { clinicaltrials.gov } \\
\text { registration number (name) }\end{array}$ & Phase & ICI Combinations (drug class) \\
\hline NCT03508570 & I & \multirow{3}{*}{ Nivolumab + Ipilimumab } \\
\hline NCT03355976 & II & \\
\hline NCT02834013 & II & \\
\hline NCT03959761 & I-II & Nivolumab (IP) + Surgery plus HIPEC \\
\hline NCT02737787 & $\mathrm{I}$ & Nivolumab + WT1 or NY-ESO-1 (vaccine) \\
\hline NCT03522246 (ATHENA) & III & Nivolumab + Rucaparib (PARPi) \\
\hline NCT02873962 & II & Nivolumab + Bevacizumab (anti-VEGF) \pm Rucaparib \\
\hline NCT04611126 & I-II & Nivolumab + Relatimab (anti-LAG-3) + Ipilimumab + ACT \\
\hline NCT03100006 & IB-IIA & Nivolumab + Oregovomab (anti-Ca125) \\
\hline NCT04620954 (ORION-02) & I-II & Nivolumab + Oregovomab + PLD + CBDCA \\
\hline NCT03667716 & $\mathrm{I}$ & Nivolumab + COM701 (PVRIG inhibitor) \\
\hline NCT04570839 & I-II & Nivolumab + COM701 + BMS-986207 (anti-TIGIT) \\
\hline NCT04514484 & $\mathrm{I}$ & Nivolumab + Cabozantinib $(T K I)$ \\
\hline NCT02335918 & I-II & Nivolumab, Varlilumab (anti-CD27) \\
\hline NCT02526017 & I & Nivolumab + Cabiralizumab (anti-CSF1R) \\
\hline NCT02440425 & II & Pembrolizumab + Paclitaxel \\
\hline NCT03029598 & I-II & \multirow{2}{*}{ Pembrolizumab + CBDCA } \\
\hline NCT04387227 & II & \\
\hline NCT04575961 (PERCEPTION) & II & Pembrolizumab + Platinum-based CTx \\
\hline NCT02766582 & II & \multirow{5}{*}{ Pembrolizumab + CBDCA + Paclitaxel } \\
\hline NCT02834975 & II & \\
\hline $\begin{array}{l}\text { NCT03410784 } \\
\text { (MITO28MaNGOov4) }\end{array}$ & II & \\
\hline NCT02520154 & II & \\
\hline NCT03126812 & I-II & \\
\hline NCT03539328 & II & Pembrolizumab + Gemcitabine or Paclitaxel or PLD vs. CTx \\
\hline NCT02900560 & II & Pembrolizumab \pm Azacitidine \\
\hline NCT02901899 & II & Pembrolizumab + Guadecitabine \\
\hline NCT03596281 (PEMBOV) & $\mathrm{I}$ & Pembrolizumab + Bevacizumab + PLD \\
\hline NCT04417192 (OLAPem) & II & Pembrolizumab + Olaparib \\
\hline $\begin{array}{l}\text { NCT03740165 (MK-7339- } \\
\text { 001/KEYLYNK-001/ENGOT- } \\
\text { ov43/GOG-3036) }\end{array}$ & III & $\begin{aligned} \text { CBDCA + Paclitaxel } & \rightarrow \text { Pembrolizumab + Olaparib vs. Pembrolizumab } \\
& + \text { PBO vs. } \mathrm{PBO}+\text { Olaparib }\end{aligned}$ \\
\hline NCT04519151 & II & Pembrolizumab + Lenvatinib \\
\hline
\end{tabular}




\begin{tabular}{|c|c|c|}
\hline $\begin{array}{l}\text { NCT03797326 (MK-7902-005/ } \\
\text { E7080-G000-224/LEAP-005) }\end{array}$ & II & \\
\hline NCT04781088 & II & Pembrolizumab + Lenvatinib + Paclitaxel \\
\hline NCT02606305 & I-II & Pembrolizumab + Mirvetuximab soravtansine (anti-FR $\alpha A D C)$ \\
\hline NCT03734692 & I-II & Pembrolizumab + IP Rintatolimod (anti-TLR3) + Cisplatin \\
\hline NCT03158935 (ACTIVATE) & & Pembrolizumab + Cyclophosphamide + autologous TILs + IL-2 \\
\hline NCT03029403 & II & Pembrolizumab + DPX-Survivac (vaccine) + Cyclophosphamide \\
\hline NCT03113487 & II & Pembrolizumab + p53 MVA (vaccine) \\
\hline NCT04713514 (TEDOVA) & II & Pembrolizumab + OSE2101 vs. OSE2101 (multi-epitope vaccine) \\
\hline NCT03558139 & $\mathrm{I}$ & Avelumab + Magrolimab (anti-CD47) \\
\hline NCT04510584 & II & Atezolizumab + Bevacizumab \\
\hline NCT02891824 (ATALANTE) & III & $\begin{array}{c}\text { Atezolizumab + Bevacizumab + platinum-based Ctx vs. PBO + } \\
\text { Bevacizumab + platinum-based Ctx }\end{array}$ \\
\hline NCT03353831 & III & Atezolizumab + Bevacizumab + Ctx vs- Bevacizumab + Ctx \\
\hline NCT02839707 & II-III & Atezolizumab + Bevacizumab + PLD \\
\hline NCT02659384 & II & Atezolizumab + Bevacizumab \pm acetylsalicylic acid \\
\hline NCT03363867 (BEACON) & II & Atezolizumab + Bevacizumab + Cobimetinib \\
\hline NCT03695380 & $\mathrm{I}$ & Atezolizumab + Cobimetinib $($ anti-MEK) + Niraparib \\
\hline NCT03598270 (ANITA) & III & $\begin{array}{c}\text { Atezolizumab + Platinum-based Ctx vs. platinum-based Ctx } \rightarrow \\
\text { Niraparib } \pm \text { Atezolizumab maintenance }\end{array}$ \\
\hline NCT02914470 (PROLOG) & I & Atezolizumab + CBDCA + Cyclophosphamide \\
\hline NCT03206047 & I-II & Atezolizumab + Guadecitabine + CDX-1401 (vaccine) \\
\hline NCT03073525 & II & Atezolizumab + Vigil (cancer cell therapy) \\
\hline NCT01975831 & I & \\
\hline NCT02953457 & II & Durvalumab + Tremelimumab \\
\hline NCT03026062 & II & \\
\hline NCT04644289(WoO) & II & Durvalumab + Olaparib \\
\hline NCT04742075 (DOVACC) & II & Durvalumab + Olaparib + UV-1 \\
\hline NCT04015739 (BOLD) & II & Durvalumab + Olaparib + Bevacizumab \\
\hline NCT03737643 (DUO-O) & III & $\begin{array}{c}\text { Durvalumab }+ \text { platinum-based Ctx }+ \text { Bevazicumab vs. PBO }+ \\
\text { platinum-based Ctx }+ \text { Bevacizumab } \rightarrow \text { Durvalumab }+ \text { Bevacizumab }+ \\
\text { Olaparib maintenance }\end{array}$ \\
\hline NCT03699449 (AMBITION) & II & Durvalumab + Tremelimumab or Olaparib or Cediranib or Ctx \\
\hline NCT02726997 (N-Dur) & I-II & Durvalumab + CBDCA + Paclitaxel \\
\hline NCT03430518 & I & Durvalumab + Eribuline \\
\hline NCT03085225 (TRAMUNE) & $\mathrm{I}$ & Durvalumab + Trabectedin \\
\hline NCT02811497 (METADUR) & II & Durvalumab + Azacitidine \\
\hline NCT02764333 & II & Durvalumab + TPIV200 (anti-FR vaccine) \\
\hline NCT02725489 & II & Durvalumab + Vigil \\
\hline NCT03267589 & II & $\begin{array}{l}\text { Durvalumab + Tremelimumab + MEDI } 9447(\text { anti-CD73 Ab) + MEDI } \\
0562(\text { anti-OX40) }\end{array}$ \\
\hline NCT04019288 & I-II & Durvalumab + AVB-S6-500 (Anti-AXL Fusion Protein) \\
\hline NCT03277482 & $\mathrm{I}$ & Durvalumab + Tremelimumab + RT \\
\hline NCT02571725 & II & Tremelimumab + Olaparib \\
\hline NCT03602859 & III & Dostarlimab (anti-PD1) + Ctx vs. Ctx + Niraparib vs. Ctx + PBO \\
\hline
\end{tabular}

ACT: adoptive cell therapy; ADC: antibody drug conjugate; CBDCA: carboplatin; CD: cluster of differentiation; CSF1R: Colony stimulating factor 1 receptor; FR $\alpha$ : folate receptor alpha; HIPEC: Hyperthermic intraperitoneal chemotherapy; IL-2: Interleukin-2; IP: intra-peritoneal; LAG-3: Lymphocyte-activation gene 3; MVA: Modified Vaccinia Virus Ankara; NY-ESO-1: New York Esophageal Squamous Cell Carcinoma-1; PBO: placebo; PLD: pegylated liposomal doxorubicin; PVRIG: poliovirus receptor related immunoglobulin domain containing; RT: Radiation Therapy; TIGIT: T-cell immunoreceptor with immunoglobulin and immunoreceptor tyrosine-based inhibitory motif; TIL: tumor-infiltrating lymphocytes; TKI: tyrosine-kinase inhibitor; TLR3: TollLike Receptor 3; VEGF: vascular-endothelial growth factor; WT1: Wilms tumor 1; 5-FU: 5-Fluorouracile 


\title{
5. Conclusions
}

So far, OC remains one of the few malignancies in which ICIs have not changed the standard of care, and neither monotherapies nor combinations have been approved. Further combinations will strengthen the efficacy of ICIs in the OC. The combinations of ICIs with anti-VEGF agents or PARP-inhibitors represent potentially very effective associations, and several studies examine this strategy. However, schedule and timing should be optimized in order to preserve tolerability. Combinations with other agents, such as multikinase inhibitors, immunotherapies targeting the immunosuppressive network in the TME, or vaccines, should be further explored to maximize the efficacy with minimal toxicity.

Besides PD-L1, biomarkers with a predictive role to ICIs should be investigated. Integrating such biomarkers with genomic and immunologic profiling will provide a comprehensive understanding of the $\mathrm{OC}$, guiding clinical trials towards rational therapy combinations and sequencing.

\begin{abstract}
Author Contributions: "Conceptualization, methodology, B.A.M.; software, formal analysis, investigation, data curation, writing - original draft preparation, B.A.M. and M.F.P.M.; writingreview and editing, D.L. and E.M..; visualization, validation, B.A.M., M.F.P.M., D.L. and E.M.; supervision, E.M. All authors have read and agreed to the published version of the manuscript."
\end{abstract}

Funding: This research received no external funding.

Acknowledgments: Servier Medical Art.

Conflicts of Interest: The authors declare no conflict of interest with regard to this work.

\section{References}

1. Globocan 2020. Ovary. Available online: https://gco.iarc.fr/today/data/factsheets/cancers/25-Ovary-fact-sheet.pdf (Accessed on 15 June 2021).

2. Torre, L.A.; Trabert, B.; DeSantis, C.E.; Miller, K.D.; Samimi, G.; Runowicz, C.D.; Gaudet, M.M.; Jemal, A.; Siegel, R.L. Ovarian Cancer Statistics, 2018: Ovarian Cancer Statistics, 2018. CA: A Cancer Journal for Clinicians 2018, 68, 284-296, doi:10.3322/caac. 21456.

3. Prat, J.; D’Angelo, E.; Espinosa, I. Ovarian Carcinomas: At Least Five Different Diseases with Distinct Histological Features and Molecular Genetics. Human Pathology 2018, 80, 11-27, doi:10.1016/j.humpath.2018.06.018.

4. Piccart, M.J. Randomized Intergroup Trial of Cisplatin-Paclitaxel Versus Cisplatin-Cyclophosphamide in Women With Advanced Epithelial Ovarian Cancer: Three-Year Results. Journal of the National Cancer Institute 2000, 92, 699-708, doi:10.1093/jnci/92.9.699.

5. Ozols, R.F.; Bundy, B.N.; Greer, B.E.; Fowler, J.M.; Clarke-Pearson, D.; Burger, R.A.; Mannel, R.S.; DeGeest, K.; Hartenbach, E.M.; Baergen, R. Phase III Trial of Carboplatin and Paclitaxel Compared With Cisplatin and Paclitaxel in Patients With Optimally Resected Stage III Ovarian Cancer: A Gynecologic Oncology Group Study. JCO 2003, 21, 3194-3200, doi:10.1200/JCO.2003.02.153.

6. Neijt, J.P.; Engelholm, S.A.; Tuxen, M.K.; Sørensen, P.G.; Hansen, M.; Sessa, C.; de Swart, C.A.M.; Hirsch, F.R.; Lund, B.; van Houwelingen, H.C. Exploratory Phase III Study of Paclitaxel and Cisplatin Versus Paclitaxel and Carboplatin in Advanced Ovarian Cancer. JCO 2000, 18, 3084-3092, doi:10.1200/JCO.2000.18.17.3084. 
7. McGuire, W.P.; Hoskins, W.J.; Brady, M.F.; Kucera, P.R.; Partridge, E.E.; Look, K.Y.; Clarke-Pearson, D.L.; Davidson, M. Cyclophosphamide and Cisplatin Compared with Paclitaxel and Cisplatin in Patients with Stage III and Stage IV Ovarian Cancer. N Engl J Med 1996, 334, 1-6, doi:10.1056/NEJM199601043340101.

8. Perren, T.J.; Swart, A.M.; Pfisterer, J.; Ledermann, J.A.; Pujade-Lauraine, E.; Kristensen, G.; Carey, M.S.; Beale, P.; Cervantes, A.; Kurzeder, C.; et al. A Phase 3 Trial of Bevacizumab in Ovarian Cancer. $N$ Engl J Med 2011, 365, 2484-2496, doi:10.1056/NEJMoa1103799.

9. Moore, K.; Colombo, N.; Scambia, G.; Kim, B.-G.; Oaknin, A.; Friedlander, M.; Lisyanskaya, A.; Floquet, A.; Leary, A.; Sonke, G.S.; et al. Maintenance Olaparib in Patients with Newly Diagnosed Advanced Ovarian Cancer. N Engl J Med 2018, 379, 24952505, doi:10.1056/NEJMoa1810858.

10. Robert, C. A Decade of Immune-Checkpoint Inhibitors in Cancer Therapy. Nat Commun 2020, 11, 3801, doi:10.1038/s41467020-17670-y.

11. Postow, M.A.; Callahan, M.K.; Wolchok, J.D. Immune Checkpoint Blockade in Cancer Therapy. JCO 2015, 33, 1974-1982, doi:10.1200/JCO.2014.59.4358.

12. Matulonis, U.A.; Shapira-Frommer, R.; Santin, A.D.; Lisyanskaya, A.S.; Pignata, S.; Vergote, I.; Raspagliesi, F.; Sonke, G.S.; Birrer, M.; Provencher, D.M.; et al. Antitumor Activity and Safety of Pembrolizumab in Patients with Advanced Recurrent Ovarian Cancer: Results from the Phase II KEYNOTE-100 Study. Annals of Oncology 2019, 30, 1080-1087, doi:10.1093/annonc/mdz135.

13. Matulonis, U.A.; Shapira, R.; Santin, A.; Lisyanskaya, A.S.; Pignata, S.; Vergote, S.; Raspagliesi, F.; Sonke, G.S.; Birrer, M.; Sehouli, J.; et al. Final results from the KEYNOTE-100 trial of pembrolizumab in patients with advanced recurrent ovarian cancer. JCO 2020, 38:15_suppl, 6005-6005, doi:10.1200/JCO.2020.38.15_suppl.6005.

14. Varga, A.; Piha-Paul, S.; Ott, P.A.; Mehnert, J.M.; Berton-Rigaud, D.; Morosky, A.; Yang, P.; Ruman, J.; Matei, D. Pembrolizumab in Patients with Programmed Death Ligand 1-Positive Advanced Ovarian Cancer: Analysis of KEYNOTE-028. Gynecologic Oncology 2019, 152, 243-250, doi:10.1016/j.ygyno.2018.11.017.

15. Matulonis U, Barry W, Penson R, et al. Phase II study of pembrolizumab (pembro) combined with pegylated liposomal doxorubicin (PLD) for recurrent platinum-resistant ovarian, fallopian tube or peritoneal cancer. SGO Annual Meeting. 2018;149:2427

16. Zsiros, E.; Lynam, S.; Attwood, K.M.; Wang, C.; Chilakapati, S.; Gomez, E.C.; Liu, S.; Akers, S.; Lele, S.; Frederick, P.J.; et al. Efficacy and Safety of Pembrolizumab in Combination With Bevacizumab and Oral Metronomic Cyclophosphamide in the Treatment of Recurrent Ovarian Cancer: A Phase 2 Nonrandomized Clinical Trial. JAMA Oncol 2021, 7, 78, doi:10.1001/jamaoncol.2020.5945.

17. Konstantinopoulos, P.A.; Waggoner, S.; Vidal, G.A.; Mita, M.; Moroney, J.W.; Holloway, R.; Van Le, L.; Sachdev, J.C.; Chapman-Davis, E.; Colon-Otero, G.; et al. Single-Arm Phases 1 and 2 Trial of Niraparib in Combination With Pembrolizumab in Patients With Recurrent Platinum-Resistant Ovarian Carcinoma. JAMA Oncol 2019, 5, 1141, doi:10.1001/jamaoncol.2019.1048.

18. Hamanishi, J.; Mandai, M.; Ikeda, T.; Minami, M.; Kawaguchi, A.; Murayama, T.; Kanai, M.; Mori, Y.; Matsumoto, S.; Chikuma, S.; et al. Safety and Antitumor Activity of Anti-PD-1 Antibody, Nivolumab, in Patients With Platinum-Resistant Ovarian Cancer. JCO 2015, 33, 4015-4022, doi:10.1200/JCO.2015.62.3397.

19. Zamarin, D.; Burger, R.A.; Sill, M.W.; Powell, D.J.; Lankes, H.A.; Feldman, M.D.; Zivanovic, O.; Gunderson, C.; Ko, E.; Mathews, C.; et al. Randomized Phase II Trial of Nivolumab Versus Nivolumab and Ipilimumab for Recurrent or Persistent Ovarian Cancer: An NRG Oncology Study. JCO 2020, 38, 1814-1823, doi:10.1200/JCO.19.02059.

20. Liu, J.F.; Herold, C.; Gray, K.P.; Penson, R.T.; Horowitz, N.; Konstantinopoulos, P.A.; Castro, C.M.; Hill, S.J.; Curtis, J.; Luo, W.; et al. Assessment of Combined Nivolumab and Bevacizumab in Relapsed Ovarian Cancer: A Phase 2 Clinical Trial. JAMA Oncol 2019, 5, 1731, doi:10.1001/jamaoncol.2019.3343. 
21. Omatsu, K.; Hamanishi, J.; Katsumata, N.; Nishio, S.; Sawada, K.; Takeuchi, S.; Aoki, D.; Fujiwara, K.; Sugiyama, T.; Konishi, I. $807 \mathrm{O}$ Nivolumab versus Gemcitabine or Pegylated Liposomal Doxorubicin for Patients with Platinum-Resistant (Advanced or Recurrent) Ovarian Cancer: Open-Label, Randomized Trial in Japan (NINJA Trial). Annals of Oncology 2020, 31, S611, doi:10.1016/j.annonc.2020.08.946.

22. Disis, M.L.; Taylor, M.H.; Kelly, K.; Beck, J.T.; Gordon, M.; Moore, K.M.; Patel, M.R.; Chaves, J.; Park, H.; Mita, A.C.; et al. Efficacy and Safety of Avelumab for Patients With Recurrent or Refractory Ovarian Cancer: Phase 1b Results From the JAVELIN Solid Tumor Trial. JAMA Oncol 2019, 5, 393, doi:10.1001/jamaoncol.2018.6258.

23. Ledermann, J.A.; Colombo, N.; Oza, A.M.; Fujiwara, K.; Birrer, M.J.; Randall, L.M.; Poddubskaya, E.V.; Scambia, G.; Shparyk, Y.V.; Lim, M.C.; et al. Avelumab in Combination with and/or Following Chemotherapy vs Chemotherapy Alone in Patients with Previously Untreated Epithelial Ovarian Cancer: Results from the Phase 3 Javelin Ovarian 100 Trial. Gynecologic Oncology 2020, 159, 13-14, doi:10.1016/j.ygyno.2020.06.025.

24. NCT03642132: Avelumab and Talazoparib in Untreated Advanced Ovarian Cancer (JAVELIN OVARIAN PARP 100). Available online: https://clinicaltrials.gov/ct2/show/NCT03642132 (Accessed on 15 June 2021).

25. Pujade-Lauraine, E.; Fujiwara, K.; Ledermann, J.A.; Oza, A.M.; Kristeleit, R.S.; Ray-Coquard, I.L.; Richardson, G.E.; Sessa, C.; Yonemori, K.; Banerjee, S.; et al. Avelumab Alone or in Combination with Pegylated Liposomal Doxorubicin versus Pegylated Liposomal Doxorubicin Alone in Platinum-Resistant or Refractory Epithelial Ovarian Cancer: Primary and Biomarker Analysis of the Phase III JAVELIN Ovarian 200 Trial. Gynecologic Oncology 2019, 154, 21-22, doi:10.1016/j.ygyno.2019.04.053.

26. Cadoo, K.A.; Meyers, M.L.; Burger, R.A.; Armstrong, D.K.; Penson, R.T.; Gordon, M.S.; Fleming, G.F.; Moroney, J.W.; Hamilton, E.P.; Duska, L.R.; et al. A Phase II Randomized Study of Avelumab plus Entinostat versus Avelumab plus Placebo in Patients (Pts) with Advanced Epithelial Ovarian Cancer (EOC). JCO 2019, 37, 5511-5511, doi:10.1200/JCO.2019.37.15_suppl.5511.

27. Moore, K.N.; Bookman, M.; Sehouli, J.; Miller, A.; Anderson, C.; Scambia, G.; Myers, T.; Taskiran, C.; Robison, K.; Mäenpää, J.; et al. Atezolizumab, Bevacizumab, and Chemotherapy for Newly Diagnosed Stage III or IV Ovarian Cancer: Placebo-Controlled Randomized Phase III Trial (IMagyn050/GOG 3015/ENGOT-OV39). JCO 2021, 39, 1842-1855, doi:10.1200/JCO.21.00306.

28. O’Cearbhaill, R.E.; Wolfer, A.; Disilvestro, P.; O’Malley, D.M.; Sabbatini, P.; Shohara, L.; Schwarzenberger, P.O.; Ricciardi, T.; Macri, M.; Ryan, A.; et al. A Phase I/II Study of Chemo-Immunotherapy with Durvalumab (Durva) and Pegylated Liposomal Doxorubicin (PLD) in Platinum-Resistant Recurrent Ovarian Cancer (PROC). Annals of Oncology 2018, 29, viii337, doi:10.1093/annonc/mdy285.153.

29. Drew, Y.; de Jonge, M.; Hong, S.H.; Park, Y.H.; Wolfer, A.; Brown, J.; Ferguson, M.; Gore, M.E.; Alvarez, R.H.; Gresty, C.; et al. An Open-Label, Phase II Basket Study of Olaparib and Durvalumab (MEDIOLA): Results in Germline BRCA -Mutated ( GBRCA m) Platinum-Sensitive Relapsed (PSR) Ovarian Cancer (OC). Gynecologic Oncology 2018, 149, 246-247, doi:10.1016/j.ygyno.2018.04.555.

30. Drew, Y.; Kaufman, B.; Banerjee, S.; Lortholary, A.; Hong, S.H.; Park, Y.H.; Zimmermann, S.; Roxburgh, P. ; Ferguson, M.; Alvarez, R.H.; et al. Phase II study of olaparib 1 durvalumab (MEDIOLA): Updated results in germline BRCA-mutated platinumsensitive relapsed (PSR) ovarian cancer (OC). Annals of Oncology 2019, 30_suppl5, v485-486, doi:10.1093/annonc/mdz253

31. Drew, Y.; Penson, R.T.; O’Malley, D.M.; Kim, J.-W.; Zimmermann, S.; Roxburgh, P.; Sohn, J.; Stemmer, S.M.; Bastian, S.; Ferguson, M.; et al. 814MO Phase II Study of Olaparib (O) plus Durvalumab (D) and Bevacizumab (B) (MEDIOLA): Initial Results in Patients (Pts) with Non-Germline BRCA-Mutated (Non-GBRCAm) Platinum Sensitive Relapsed (PSR) Ovarian Cancer (OC). Annals of Oncology 2020, 31, S615-S616, doi:10.1016/j.annonc.2020.08.953.

32. Lee, J.M.; Cimino-Mathews, A.; Peer, C.J.; Zimmer, A.; Lipkowitz, S.; Annunziata, C.M.; Cao, L.; Harrell, M.I.; Swisher, E.M.; Houston, N.; et al. Safety and Clinical Activity of the Programmed Death-Ligand 1 Inhibitor Durvalumab in Combination With Poly (ADP-Ribose) Polymerase Inhibitor Olaparib or Vascular Endothelial Growth Factor Receptor 1-3 Inhibitor Cediranib in Women's Cancers: A Dose-Escalation, Phase I Study. JCO 2017, 35, 2193-2202, doi:10.1200/JCO.2016.72.1340. 
33. Lampert, E.J.; Zimmer, A.; Padget, M.; Cimino-Mathews, A.; Nair, J.R.; Liu, Y.; Swisher, E.M.; Hodge, J.W.; Nixon, A.B.; Nichols, E.; et al. Combination of PARP Inhibitor Olaparib, and PD-L1 Inhibitor Durvalumab, in Recurrent Ovarian Cancer: A Proof-of-Concept Phase II Study. Clin Cancer Res 2020, 26, 4268-4279, doi:10.1158/1078-0432.CCR-20-0056.

34. NCT01611558: Phase II Study of Ipilimumab Monotherapy in Recurrent Platinum-Sensitive Ovarian Cancer - Study Results. Available online: https://clinicaltrials.gov/ct2/show/results/NCT01611558 (Accessed on 15 June 2021).

35. Gaillard, S.; Berg, M.; Harrison, J.; Huang, P.; Leatherman, J.M.; Doucet, M.; Sen, R.; Suru, A.; Cai, H.; Durham, J.N.; et al. A Clinical Study of Tremelimumab Alone or in Combination with Olaparib in Patients with Advanced Epithelial Ovarian Cancer. JCO 2020, 38, 6045-6045, doi:10.1200/JCO.2020.38.15_suppl.6045.

36. Adams, S.F.; Rixe, O.; Lee, J.-H.; McCance, D.J.; Westgate, S.; Eberhardt, S.C.; Rutledge, T.; Muller, C. Phase I Study Combining Olaparib and Tremelimumab for the Treatment of Women with BRCA-Deficient Recurrent Ovarian Cancer. JCO 2017, 35, e17052-e17052, doi:10.1200/JCO.2017.35.15_suppl.e17052.

37. Hartnett, E.G.; Knight, J.; Radolec, M.; Buckanovich, R.J.; Edwards, R.P.; Vlad, A.M. Immunotherapy Advances for Epithelial Ovarian Cancer. Cancers 2020, 12, 3733, doi:10.3390/cancers12123733.

38. Ning, F.; Cole, C.B.; Annunziata, C.M. Driving Immune Responses in the Ovarian Tumor Microenvironment. Front. Oncol. 2021, 10, 604084, doi:10.3389/fonc.2020.604084.

39. Yang, Y.; Yang, Y.; Yang, J.; Zhao, X.; Wei, X. Tumor Microenvironment in Ovarian Cancer: Function and Therapeutic Strategy. Front. Cell Dev. Biol. 2020, 8, 758, doi:10.3389/fcell.2020.00758.

40. Konstantinopoulos, P.A.; Cannistra, S.A. Immune Checkpoint Inhibitors in Ovarian Cancer: Can We Bridge the Gap Between IMagynation and Reality? JCO 2021, 10, 39, 1833-1838, doi:10.1200/JCO.21.00571.

41. Kapka-Skrzypczak, L.; Wolinska, E.; Szparecki, G.; Czajka, M.; Skrzypczak, M. The Immunohistochemical Analysis of Membrane-Bound CD55, CD59 and Fluid-Phase FH and FH-like Complement Inhibitors in Cancers of Ovary and Corpus Uteri Origin. Cent Eur J Immunol. 2015, 3, 349-353, doi:10.5114/ceji.2015.54598.

42. Wouters, M.; Dijkgraaf, E.; Kuijjer, M.; Jordanova, E.; Hollema, H.; Welters, M.; van der Hoeven, J.; Daemen, T.; Kroep, J.; Nijman, H.; et al. Interleukin-6 Receptor and Its Ligand Interleukin-6 Are Opposite Markers for Survival and Infiltration with Mature Myeloid Cells in Ovarian Cancer. OncoImmunology 2014, 3, e962397, doi:10.4161/21624011.2014.962397.

43. Kolomeyevskaya, N.; Eng, K.H.; Khan, A.N.H.; Grzankowski, K.S.; Singel, K.L.; Moysich, K.; Segal, B.H. Cytokine Profiling of Ascites at Primary Surgery Identifies an Interaction of Tumor Necrosis Factor- $\alpha$ and Interleukin-6 in Predicting Reduced Progression-Free Survival in Epithelial Ovarian Cancer. Gynecologic Oncology 2015, 138, 352-357, doi:10.1016/j.ygyno.2015.05.009.

44. Wong, J.L.; Obermajer, N.; Odunsi, K.; Edwards, R.P.; Kalinski, P. Synergistic COX2 Induction by IFN $\gamma$ and TNF $\alpha$ Self-Limits Type-1 Immunity in the Human Tumor Microenvironment. Cancer Immunol Res 2016, 4, 303-311, doi:10.1158/2326-6066.CIR$15-0157$.

45. Motz, G.T.; Santoro, S.P.; Wang, L.-P.; Garrabrant, T.; Lastra, R.R.; Hagemann, I.S.; Lal, P.; Feldman, M.D.; Benencia, F.; Coukos, G. Tumor Endothelium FasL Establishes a Selective Immune Barrier Promoting Tolerance in Tumors. Nat Med 2014, 20, 607-615, doi:10.1038/nm.3541.

46. Pollard, J.W. Tumour-Educated Macrophages Promote Tumour Progression and Metastasis. Nat Rev Cancer 2004, 4, 71-78, doi:10.1038/nrc1256.

47. Reinartz, S.; Schumann, T.; Finkernagel, F.; Wortmann, A.; Jansen, J.M.; Meissner, W.; Krause, M.; Schwörer, A.; Wagner, U.; Müller-Brüsselbach, S.; et al. Mixed-polarization Phenotype of Ascites-associated Macrophages in Human Ovarian Carcinoma: Correlation of CD163 Expression, Cytokine Levels and Early Relapse. Int. J. Cancer 2014, 134, 32-42, doi:10.1002/ijc.28335. 
48. Yin, M.; Li, X.; Tan, S.; Zhou, H.J.; Ji, W.; Bellone, S.; Xu, X.; Zhang, H.; Santin, A.D.; Lou, G.; et al. Tumor-Associated Macrophages Drive Spheroid Formation during Early Transcoelomic Metastasis of Ovarian Cancer. Journal of Clinical Investigation 2016, 126, 4157-4173, doi:10.1172/JCI87252.

49. Zhang, M.; He, Y.; Sun, X.; Li, Q.; Wang, W.; Zhao, A.; Di, W. A High M1/M2 Ratio of Tumor-Associated Macrophages Is Associated with Extended Survival in Ovarian Cancer Patients. J Ovarian Res 2014, 7, 19, doi:10.1186/1757-2215-7-19.

50. Lan, C.; Huang, X.; Lin, S.; Huang, H.; Cai, Q.; Wan, T.; Lu, J.; Liu, J. Expression of M2-Polarized Macrophages Is Associated with Poor Prognosis for Advanced Epithelial Ovarian Cancer. Technol Cancer Res Treat 2013, 12, 259-267, doi:10.7785/tcrt.2012.500312.

51. Yuan, X.; Zhang, J.; Li, D.; Mao, Y.; Mo, F.; Du, W.; Ma, X. Prognostic Significance of Tumor-Associated Macrophages in Ovarian Cancer: A Meta-Analysis. Gynecologic Oncology 2017, 147, 181-187, doi:10.1016/j.ygyno.2017.07.007.

52. Gordon, S. Alternative Activation of Macrophages. Nat Rev Immunol 2003, 3, 23-35, doi:10.1038/nri978.

53. Li, H.; Fan, X.; Houghton, J. Tumor Microenvironment: The Role of the Tumor Stroma in Cancer. J. Cell. Biochem. 2007, 101, 805-815, doi:10.1002/jcb.21159.

54. Curiel, T.J.; Coukos, G.; Zou, L.; Alvarez, X.; Cheng, P.; Mottram, P.; Evdemon-Hogan, M.; Conejo-Garcia, J.R.; Zhang, L.; Burow, M.; et al. Specific Recruitment of Regulatory T Cells in Ovarian Carcinoma Fosters Immune Privilege and Predicts Reduced Survival. Nat Med 2004, 10, 942-949, doi:10.1038/nm1093.

55. Schmidt, A.; Oberle, N.; Krammer, P.H. Molecular Mechanisms of Treg-Mediated T Cell Suppression. Front. Immun. 2012, 3 , doi:10.3389/fimmu.2012.00051.

56. Obermajer, N.; Muthuswamy, R.; Lesnock, J.; Edwards, R.P.; Kalinski, P. Positive Feedback between PGE2 and COX2 Redirects the Differentiation of Human Dendritic Cells toward Stable Myeloid-Derived Suppressor Cells. Blood 2011, 118, 54985505, doi:10.1182/blood-2011-07-365825.

57. Howitt, B.E.; Strickland, K.C.; Sholl, L.M.; Rodig, S.; Ritterhouse, L.L.; Chowdhury, D.; D’Andrea, A.D.; Matulonis, U.A.; Konstantinopoulos, P.A. Clear Cell Ovarian Cancers with Microsatellite Instability: A Unique Subset of Ovarian Cancers with Increased Tumor-Infiltrating Lymphocytes and PD-1/PD-L1 Expression. OncoImmunology 2017, 6, e1277308, doi:10.1080/2162402X.2016.1277308.

58. Oda, K.; Hamanishi, J.; Matsuo, K.; Hasegawa, K. Genomics to Immunotherapy of Ovarian Clear Cell Carcinoma: Unique Opportunities for Management. Gynecologic Oncology 2018, 151, 381-389, doi:10.1016/j.ygyno.2018.09.001.

59. Verhaak, R.G.W.; Tamayo, P.; Yang, J.-Y.; Hubbard, D.; Zhang, H.; Creighton, C.J.; Fereday, S.; Lawrence, M.; Carter, S.L.; Mermel, C.H.; et al. Prognostically Relevant Gene Signatures of High-Grade Serous Ovarian Carcinoma. J. Clin. Invest. 2012, JCI65833, doi:10.1172/JCI65833.

60. Przybytkowski, E.; Davis, T.; Hosny, A.; Eismann, J.; Matulonis, U.A.; Wulf, G.M.; Nabavi, S. An Immune-Centric Exploration of BRCA1 and BRCA2 Germline Mutation Related Breast and Ovarian Cancers. BMC Cancer 2020, 20, 197, doi:10.1186/s12885020-6605-1.

61. Strickland, K.C.; Howitt, B.E.; Shukla, S.A.; Rodig, S.; Ritterhouse, L.L.; Liu, J.F.; Garber, J.E.; Chowdhury, D.; Wu, C.J.; D'Andrea, A.D.; et al. Association and Prognostic Significance of BRCA1/2-Mutation Status with Neoantigen Load, Number of Tumor-Infiltrating Lymphocytes and Expression of PD-1/PD-L1 in High Grade Serous Ovarian Cancer. Oncotarget 2016, 7, 1358713598, doi:10.18632/oncotarget.7277.

62. Morse, C.B.; Toukatly, M.N.; Kilgore, M.R.; Agnew, K.J.; Bernards, S.S.; Norquist, B.M.; Pennington, K.P.; Garcia, R.L.; Liao, J.B.; Swisher, E.M. Tumor Infiltrating Lymphocytes and Homologous Recombination Deficiency Are Independently Associated with Improved Survival in Ovarian Carcinoma. Gynecologic Oncology 2019, 153, 217-222, doi:10.1016/j.ygyno.2019.02.011. 
63. McAlpine, J.N.; Porter, H.; Köbel, M.; Nelson, B.H.; Prentice, L.M.; Kalloger, S.E.; Senz, J.; Milne, K.; Ding, J.; Shah, S.P.; et al. BRCA1 and BRCA2 Mutations Correlate with TP53 Abnormalities and Presence of Immune Cell Infiltrates in Ovarian HighGrade Serous Carcinoma. Mod Pathol 2012, 25, 740-750, doi:10.1038/modpathol.2011.211.

64. Gadducci, A.; Guerrieri, M.E. PARP Inhibitors Alone and in Combination with Other Biological Agents in Homologous Recombination Deficient Epithelial Ovarian Cancer: From the Basic Research to the Clinic. Critical Reviews in Oncology/Hematology 2017, 114, 153-165, doi:10.1016/j.critrevonc.2017.04.006.

65. Deshpande, M.; Romanski, P.A.; Rosenwaks, Z.; Gerhardt, J. Gynecological Cancers Caused by Deficient Mismatch Repair and Microsatellite Instability. Cancers 2020, 12, 3319, doi:10.3390/cancers12113319.

66. Helder-Woolderink, J.M.; Blok, E.A.; Vasen, H.F.A.; Hollema, H.; Mourits, M.J.; De Bock, G.H. Ovarian Cancer in Lynch Syndrome; a Systematic Review. European Journal of Cancer 2016, 55, 65-73, doi:10.1016/j.ejca.2015.12.005.

67. van Zyl, B.; Tang, D.; Bowden, N.A. Biomarkers of Platinum Resistance in Ovarian Cancer: What Can We Use to Improve Treatment. Endocrine-Related Cancer 2018, 25, R303-R318, doi:10.1530/ERC-17-0336.

68. Le, D.T.; Uram, J.N.; Wang, H.; Bartlett, B.R.; Kemberling, H.; Eyring, A.D.; Skora, A.D.; Luber, B.S.; Azad, N.S.; Laheru, D.; et al. PD-1 Blockade in Tumors with Mismatch-Repair Deficiency. $N$ Engl J Med 2015, 372, 2509-2520, doi:10.1056/NEJMoa1500596.

69. Shen, J.; Zhao, W.; Ju, Z.; Wang, L.; Peng, Y.; Labrie, M.; Yap, T.A.; Mills, G.B.; Peng, G. PARPi Triggers the STINGDependent Immune Response and Enhances the Therapeutic Efficacy of Immune Checkpoint Blockade Independent of BRCAness. Cancer Res 2019, 79, 311-319, doi:10.1158/0008-5472.CAN-18-1003.

70. Vikas, P.; Borcherding, N.; Chennamadhavuni, A.; Garje, R. Therapeutic Potential of Combining PARP Inhibitor and Immunotherapy in Solid Tumors. Front. Oncol. 2020, 10, 570, doi:10.3389/fonc.2020.00570.

71. Rébé, C.; Demontoux, L.; Pilot, T.; Ghiringhelli, F. Platinum Derivatives Effects on Anticancer Immune Response. Biomolecules 2019, 10, 13, doi:10.3390/biom 10010013.

72. Grabosch, S.; Bulatovic, M.; Zeng, F.; Ma, T.; Zhang, L.; Ross, M.; Brozick, J.; Fang, Y.; Tseng, G.; Kim, E.; et al. CisplatinInduced Immune Modulation in Ovarian Cancer Mouse Models with Distinct Inflammation Profiles. Oncogene 2019, 38, 23802393, doi:10.1038/s41388-018-0581-9.

73. Wu, X.; Feng, Q.-M.; Wang, Y.; Shi, J.; Ge, H.-L.; Di, W. The Immunologic Aspects in Advanced Ovarian Cancer Patients Treated with Paclitaxel and Carboplatin Chemotherapy. Cancer Immunol Immunother 2010, 59, 279-291, doi:10.1007/s00262-0090749-9.

74. de Biasi, A.R.; Villena-Vargas, J.; Adusumilli, P.S. Cisplatin-Induced Antitumor Immunomodulation: A Review of Preclinical and Clinical Evidence. Clin Cancer Res 2014, 20, 5384-5391, doi:10.1158/1078-0432.CCR-14-1298.

75. Zhang, Z.; Yu, X.; Wang, Z.; Wu, P.; Huang, J. Anthracyclines Potentiate Anti-Tumor Immunity: A New Opportunity for Chemoimmunotherapy. Cancer Letters 2015, 369, 331-335, doi:10.1016/j.canlet.2015.10.002.

76. Madondo, M.T.; Quinn, M.; Plebanski, M. Low Dose Cyclophosphamide: Mechanisms of T Cell Modulation. Cancer Treatment Reviews 2016, 42, 3-9, doi:10.1016/j.ctrv.2015.11.005.

77. Mkrtichyan, M.; Najjar, Y.G.; Raulfs, E.C.; Abdalla, M.Y.; Samara, R.; Rotem-Yehudar, R.; Cook, L.; Khleif, S.N. Anti-PD-1 Synergizes with Cyclophosphamide to Induce Potent Anti-Tumor Vaccine Effects through Novel Mechanisms. Eur. J. Immunol. 2011, 41, 2977-2986, doi:10.1002/eji.201141639. 
78. Ziogas, A.C.; Gavalas, N.G.; Tsiatas, M.; Tsitsilonis, O.; Politi, E.; Terpos, E.; Rodolakis, A.; Vlahos, G.; Thomakos, N.; Haidopoulos, D.; et al. VEGF Directly Suppresses Activation of T Cells from Ovarian Cancer Patients and Healthy Individuals via VEGF Receptor Type 2. Int. J. Cancer 2012, 130, 857-864, doi:10.1002/ijc.26094.

79. Shrimali, R.K.; Yu, Z.; Theoret, M.R.; Chinnasamy, D.; Restifo, N.P.; Rosenberg, S.A. Antiangiogenic Agents Can Increase Lymphocyte Infiltration into Tumor and Enhance the Effectiveness of Adoptive Immunotherapy of Cancer. Cancer Res 2010, 70, 6171-6180, doi:10.1158/0008-5472.CAN-10-0153.

80. Fukumura, D.; Kloepper, J.; Amoozgar, Z.; Duda, D.G.; Jain, R.K. Enhancing Cancer Immunotherapy Using Antiangiogenics: Opportunities and Challenges. Nat Rev Clin Oncol 2018, 15, 325-340, doi:10.1038/nrclinonc.2018.29.

81. Chow, S.; Berek, J.S.; Dorigo, O. Development of Therapeutic Vaccines for Ovarian Cancer. Vaccines 2020, 8, 657, doi:10.3390/vaccines8040657.

82. Shih, I.; Kurman R.J. Ovarian Tumorigenesis: a Proposed Model Based on Morphological and Molecular Genetic Analysis. Am J Pathol. 2004, 164, 1511-1518, doi:10.1016/s0002-9440(10)63708-x.

83. Peoples, G.E.; Anderson, B.W.; Fisk, B.; Kudelka, A.P.; Wharton, J.T.; Ioannides, C.G. Ovarian Cancer-Associated Lymphocyte Recognition of Folate Binding Protein Peptides. Ann Surg Oncol. 1998, 5, 743-750, doi:10.1007/BF02303486.

84. Odunsi, K.; Jungbluth, A.A.; Stockert, E.; Qian, F.; Gnjatic, S.; Tammela, J.; Intengan, M.; Beck, A.; Keitz, B.; Santiago, D.; et al. NY-ESO-1 and LAGE-1 Cancer-Testis Antigens Are Potential Targets for Immunotherapy in Epithelial Ovarian Cancer. Cancer Res. 2003, 63, 6076-6083.

85. Felder, M.; Kapur, A.; Gonzalez-Bosquet, J.; Horibata, S.; Heintz, J.; Albrecht, R.; Fass, L.; Kaur, J.; Hu, K.; Shojaei, H.; et al. MUC16 (CA125): Tumor Biomarker to Cancer Therapy, a Work in Progress. Mol. Cancer. 2014, 13, 129, doi:10.1186/1476-459813-129.

86. Parvathareddy, S.K.; Siraj, A.K.; Al-Badawi, I.A.; Tulbah, A.; Al-Dayel, F.; Al-Kuraya, K.S. Differential Expression of PD-L1 between Primary and Metastatic Epithelial Ovarian Cancer and Its Clinico-Pathological Correlation. Sci Rep 2021, 11, 3750, doi:10.1038/s41598-021-83276-Z.

87. Wang, Q.; Lou, W.; Di, W.; Wu, X. Prognostic Value of Tumor PD-L1 Expression Combined with CD8 + Tumor Infiltrating Lymphocytes in High Grade Serous Ovarian Cancer. International Immunopharmacology 2017, 52, 7-14, doi:10.1016/j.intimp.2017.08.017.

88. Zhu, J.; Wen, H.; Bi, R.; Wu, Y.; Wu, X. Prognostic Value of Programmed Death-Ligand 1 (PD-L1) Expression in Ovarian Clear Cell Carcinoma. J Gynecol Oncol 2017, 28, e77, doi:10.3802/jgo.2017.28.e77.

89. Webb, J.R.; Milne, K.; Kroeger, D.R.; Nelson, B.H. PD-L1 Expression Is Associated with Tumor-Infiltrating T Cells and Favorable Prognosis in High-Grade Serous Ovarian Cancer. Gynecologic Oncology 2016, 141, 293-302, doi:10.1016/j.ygyno.2016.03.008.

90. Mesnage, S.J.L.; Auguste, A.; Genestie, C.; Dunant, A.; Pain, E.; Drusch, F.; Gouy, S.; Morice, P.; Bentivegna, E.; Lhomme, C.; et al. Neoadjuvant Chemotherapy (NACT) Increases Immune Infiltration and Programmed Death-Ligand 1 (PD-L1) Expression in Epithelial Ovarian Cancer (EOC). Annals of Oncology 2017, 28, 651-657, doi:10.1093/annonc/mdw625.

91. Kim, H.-S.; Kim, J.-Y.; Lee, Y.J.; Kim, S.H.; Lee, J.-Y.; Nam, E.J.; Kim, S.; Kim, S.W.; Kim, Y.T. Expression of Programmed Cell Death Ligand 1 and Immune Checkpoint Markers in Residual Tumors after Neoadjuvant Chemotherapy for Advanced HighGrade Serous Ovarian Cancer. Gynecologic Oncology 2018, 151, 414-421, doi:10.1016/j.ygyno.2018.08.023. 